\title{
Potential role of indoleamine 2,3-dioxygenase in primary biliary cirrhosis
}

\author{
KASHIF ASGHAR $^{1-3}$, JOHN BRAIN $^{1}$, JEREMY M. PALMER $^{1}$, STEPHEN DOUGLASS $^{1}$, \\ FATMAH M. A. NAEMI ${ }^{1}$, GRAEME O'BOYLE ${ }^{1}$, JOHN KIRBY ${ }^{1}$ and SIMI ALI $^{1}$ \\ ${ }^{1}$ Applied Immunobiology and Transplantation Research Group, Institute of Cellular Medicine, Medical School, \\ University of Newcastle, Newcastle upon Tyne NE2 4HH, UK; ${ }^{2}$ Healthcare Biotechnology Department, \\ Atta-ur-Rahman School of Applied Biosciences, National University of Sciences and Technology, Islamabad 44000; \\ ${ }^{3}$ Department of Basic Sciences Research, Shaukat Khanum Memorial Cancer Hospital \\ and Research Centre, Lahore 54000, Pakistan
}

Received November 1, 2016; Accepted June 2, 2017

DOI: $10.3892 / \mathrm{ol} .2017 .6834$

\begin{abstract}
Indoleamine 2,3-dioxygenase (IDO)-induced immunosuppression can be clinically beneficial for autoimmune diseases. Primary biliary cirrhosis (PBC) is characterized by autoimmune lesions of intrahepatic bile duct epithelial cells that may lead to irreversible cirrhosis or hepatocellular carcinoma. The present study assessed the expression and function of IDO in a cell culture model and in PBC patients. IDO expression was monitored in a human immortalized but non-malignant biliary epithelial cell (iBEC) line. Increased expression of IDO1/2 was observed in the iBECs following stimulation with interferon- $\gamma($ IFN- $\gamma)$. The induction of IDO was IFN- $\gamma$-dependent, but was independent of the transforming growth factor- $\beta$ (TGF- $\beta$ ) pathway. IDO enzymatic activity was observed in the supernatant of iBECs following stimulation with IFN- $\gamma$ using colorimetric assays. A total of 47 serum samples from $\mathrm{PBC}$ patients were used to examine IDO activity by high-performance liquid chromatography, with samples from 24 healthy volunteers used as controls. Patients with PBC exhibited an increased
\end{abstract}

Correspondence to: Professor Simi Ali, Applied Immunobiology and Transplantation Research Group, Institute of Cellular Medicine, Medical School, University of Newcastle, 3rd Floor William Leech Building, Newcastle upon Tyne NE2 4HH, UK

E-mail: simi.ali@ncl.ac.uk

Abbreviations: IDO, indoleamine 2,3-dioxygenase; PBC, primary biliary cirrhosis; iBEC, immortalized, but non-malignant, biliary epithelial cell line; HPLC, high-performance liquid chromatography; IFN- $\gamma$, interferon- $\gamma$; TGF- $\beta$, transforming growth factor- $\beta$; BEC, biliary epithelial cells; GCN2, general control non-repressed 2; 3-HAA, 3-hydroxyanthranilic acid; Kyn, kynurenine; TDO, tryptophan-2,3-dioxygenase; EAE, experimental autoimmune encephalomyelitis

Key words: indoleamine 2,3-dioxygenase, primary biliary cirrhosis, immortalized biliary epithelial cells, tryptophan metabolites rate of tryptophan to kynurenine conversion $(\mathrm{P}>0.01)$. Liver sections from patients with $\mathrm{PBC}(\mathrm{n}=5)$ and those of healthy controls $(n=5)$ were used for immunohistochemical studies. IDO expression was observed in biliary epithelial cells and in hepatocytes of PBC patients. Finally, the effect of tryptophan metabolites on human cluster of differentiation (CD) $4^{+} \mathrm{T}$ cells in inducing polarization towards a regulatory $\mathrm{T}$ cell phenotype was examined. 3-Hydroxykynurenine significantly upregulated the fraction of $\mathrm{CD}^{+}{ }^{+}$cells expressing forkhead box $\mathrm{p} 3$ (Foxp3). The results of the present study suggest a therapeutic opportunity for the management of $\mathrm{PBC}$ and indicate that tryptophan catabolism could serve as a potential biomarker to monitor disease progression.

\section{Introduction}

Indoleamine 2,3-dioxygenase (IDO) is an intracellular enzyme that acts as an immunosuppressant (1). IDO serves a crucial role in the induction of tolerance during infection, cancer and autoimmune diseases $(2,3)$. IDO expression is induced by interferon- $\gamma($ IFN- $\gamma)$ during inflammation (4). The IDO pathway includes two related but distinct enzymes encoded by genes IDO-1 and IDO-2 (5). The two IDO enzymes may have a differential range of expression and signaling pathways, and differ in their selectivity for certain inhibitors $(6,7)$. However, their specific contribution to immune regulation is not fully understood.

Primary biliary cirrhosis (PBC) is an inflammatory autoimmune disease that targets the biliary epithelial cells (BEC) in the liver. Impaired IDO generation contributes to the progress of autoimmunity in $\mathrm{PBC}$ (8). Defects in the regulatory cell niche are vital to the advancement of autoimmunity, but $\mathrm{PBC}$ is characterized by a quantitative decline in the cluster of differentiation $(\mathrm{CD}) 4^{+} \mathrm{CD} 25^{+}$forkhead box $\mathrm{p} 3$ (Foxp $3^{+}$) lymphocyte [regulatory T-cell (T-reg)] compartment that may be a key point in the pathogenesis of disease (9). It has been speculated that the destruction of the biliary tract in $\mathrm{PBC}$ is mediated by auto-reactive $\mathrm{CD}^{+}$, as well as $\mathrm{CD}^{+} \mathrm{T}$ cells $(10,11)$.

Overexpression of IDO may induce immunosuppression and tolerance; this has been established following studies in 
multiple animal models $(1,12,13)$. IDO has been shown to modulate immune response in two ways. Firstly, it depletes tryptophan, which produces a cellular stress reaction through the general control non-repressed 2 (GCN2) kinase pathway (14), leading to the production of tryptophan metabolites (15). These metabolites contribute to the immunosuppressive effects of IDO by inhibiting T-cell responses (16). Secondly, IDO induces immunosuppression by producing kynurenine (Kyn), a ligand for the aryl hydrocarbon receptor (15); this promotes differentiation of Foxp $3^{+}$T-regs and decreases the immunogenicity of dendritic cells (DCs) $(12,13)$. It has been established that human $\mathrm{T}$ cells are responsive to the anti-proliferative and cytotoxic effects of supplemented Kyns $(16,17)$. Kyns suppress proliferation and have pro-apoptotic properties, primarily in T-helper (Th) 1 lymphocytes, which respond to antigen presentation $(18,19)$. The mechanisms by which tryptophan metabolites affect $\mathrm{T}$ cells are presently ambiguous; they may have direct toxic effects or could bind to the receptor that induces T-cell death (20).

The mutual outcome of tryptophan deprivation and increased Kyn concentration depends on the GCN2 kinase-mediated downregulation of the TCR $\zeta$-chain in $\mathrm{CD} 8^{+}$ cells, reducing their cytotoxic effects (21). Furthermore, the depletion of tryptophan, together with the increased generation of tryptophan metabolites, polarizes the differentiation of naïve $\mathrm{CD} 4^{+} \mathrm{CD} 25^{-} \mathrm{T}$ cells towards a regulatory phenotype (21).

IDO is upregulated by certain cytokines and inflammatory molecules; however, its most potent stimulator is IFN- $\gamma$ (4). Transforming growth factor- $\beta$ (TGF- $\beta$ ) serves a pivotal role in establishing tolerance and preventing autoimmunity (22). IDO is an essential intermediary that links TGF- $\beta$ production by DCs with T-reg differentiation and the induction of tolerance (23). TGF- $\beta$ (24), IL-10 (25) and nitric oxide (26) are negative regulators of IDO. With the exception of IL-10, expression of these regulators in the liver of $\mathrm{PBC}$ patients is increased $(27,28)$.

In the present study, we hypothesized that IDO may have a potential role in the pathogenesis of human PBC. High IDO activity in the biliary epithelial $\mathrm{H} 69$ cell line may offer an insight into the role of IDO in the pathogenesis of PBC. Thus, the following were investigated: i) The functional enzymatic activity of IDO in the cell line and serum samples of PBC patients and controls; ii) the expression of IDO in control and PBC liver tissues; and iii) whether Kyns modulate the human $\mathrm{CD} 4^{+} \mathrm{T}$ cells polarization toward a T-reg phenotype.

\section{Materials and methods}

Patients. The present study was conducted with local regional ethics committee approval, and written informed consent for publication of this study was obtained from all patients. Samples included serum collected for the purposes of research and excess liver biopsy tissue from diagnostic procedures. The mean age of patients was 58 years, with an age range between 35 and 66 years. All samples were anonymized. To discount the variable effects due to gender difference, all patients with PBC and all healthy controls included in the study were female.

Cell culture. The H69 immortalized biliary epithelial cell (iBEC) line was created and obtained from Grubman et al (29)
(Tufts University School of Medicine, Boston, MA, USA) from human intrahepatic biliary epithelial cells and was used for the current study. These cells exhibit characteristics of normal human biliary epithelium, with expression of cytokeratin (CK)7 and 19. The iBECs were cultured in $75-\mathrm{cm}^{2}$ flasks, at $37^{\circ} \mathrm{C}$ in an atmosphere containing $5 \% \mathrm{CO}_{2}$, in a $3: 1$ mix of Dulbecco's modified Eagle's medium and Nutrient Mixture F12 Ham (Sigma-Aldrich; Merck KGaA, Darmstadt, Germany) supplemented with $1.8 \times 10^{-4} \mathrm{M}$ adenine $(24.3 \mathrm{mg} / \mathrm{l})$, $2 \times 10^{-9} \mathrm{M}$ triiodothyronine $(1.345 \mu \mathrm{g} / \mathrm{l}), 5.5 \times 10^{-6} \mathrm{M}$ epinephrine $(1.0 \mathrm{mg} / \mathrm{l})$ (all from Sigma-Aldrich; Merck KGaA), ITS-X supplement $(10 \mathrm{mg} / 1$ insulin, $5.5 \mathrm{~g} / 1$ transferrin, $2.0 \mathrm{~g} / 1$ ethanolamine and $6.7 \mu \mathrm{g} / 1$ sodium selenite; Gibco; Thermo Fisher Scientific, Inc., Waltham, MA, USA), $1 \mu \mathrm{M}$ hydrocortisone solution $(362.46 \mu \mathrm{g} / \mathrm{l}), 10 \%$ heat-inactivated fetal bovine serum and $100 \mathrm{U} / \mathrm{ml}$ each of penicillin and streptomycin (all from Sigma-Aldrich; Merck KGaA).

H69 cells treated with IFN- $\gamma$. H69 cells were treated with $20 \mathrm{ng} / \mathrm{ml}$ IFN $-\gamma$. Once confluent $(>80 \%)$, the cells were then left post- IFN- $\gamma$ treatment for $0,6,12,24,48,72,96$ and $120 \mathrm{~h}$ prior to RNA isolation or harvesting of supernatants.

H69 cells treated with TGF- $\beta$ type-1 receptor serine/threonine kinase (ALK5) inhibitor. H69 cells were incubated with an ALK5 inhibitor (SB-505124; catalog no. 3263; TOCRIS Bioscience, Bristol, UK) at an optimal concentration of $1 \mu \mathrm{M}(30)$ for $1 \mathrm{~h}$ prior to stimulation with IFN- $\gamma$ for 6 and $24 \mathrm{~h}$.

Reverse transcription-quantitative polymerase chain reaction $(R T-q P C R)$. RNA isolation was performed according to the method developed by Chomczynski and Sacchi (31). TRIzol reagent (Sigma-Aldrich; Merck KGaA) was used according to the manufacturer's instructions. RNA was quantified and quality-assessed using a NanoDrop spectrophotometer (NanoDrop ND-1000; Thermo Fisher Scientific, Logan, UT, USA). Isolated RNA was reverse transcribed to cDNA using the AffinityScript Multi Temperature cDNA Synthesis kit (Agilent Technologies, Inc., Santa Clara, CA, USA) according to the manufacturer's protocol. The qPCR experiments in this project utilized TaqMan chemistry and were performed in a MicroAmp Optical 96-well plate (both from Applied Biosystems; Thermo Fisher Scientific, Inc.) on a StepOnePlus Real-Time PCR machine (Applied Biosystems; Thermo Fisher Scientific, Inc.), with each well containing $1 \mu 1$ TaqMan primer-probe (all primers were exon-spanning), $1 \mu 1 \mathrm{cDNA}$, $10 \mu 1$ Master Mix and $8 \mu 1$ RNase-free water. Primers used were for GAPDH (catalog no. Hs02758991_g1), IDO-1 (catalog no. Hs00984148_m1), IDO-2 (catalog no. Hs01589373_m1), TGF- $\beta 1$ (catalog no. Hs00998133_m1), TGF- $\beta 2$ (catalog no. Hs00234244_m1) and were all purchased from Applied Biosystems; Thermo Fisher Scientific, Inc. The thermocycling conditions were as follows: $50^{\circ} \mathrm{C}$ for $1 \mathrm{~min}, 95^{\circ} \mathrm{C}$ for $10 \mathrm{~min}$, followed by 40 cycles of $95^{\circ} \mathrm{C}$ for $15 \mathrm{sec}$ and $60^{\circ} \mathrm{C}$ for $1 \mathrm{~min}$. Data were normalized to the expression of GAPDH mRNA using the $2^{-\Delta \Delta \mathrm{Cq}}$ method (32) and analyzed using REST 2009 software (Qiagen GmbH, Hilden, Germany).

Immunohistochemistry. Formalin-fixed, paraffin-embedded liver biopsy sections from patients were deparaffinized in 
xylene and rehydrated. Antigen retrieval was conducted by pressure-cooking (pressure, $15 \mathrm{PSI}$; temperature, $121^{\circ} \mathrm{C}$ ) for $1 \mathrm{~min}$ in Tris/EDTA ( $\mathrm{pH} 8.0$ ). To block endogenous peroxidase activity, $3 \% \mathrm{H}_{2} \mathrm{O}_{2}$ in methanol was utilized and a biotin block was performed according to the manufacturer's protocol (Avidin/Biotin Blocking kit; catalog no. SP-2001; Vector Laboratories, Ltd., Peterborough, UK). Sections were incubated either with anti-IDO antibody (catalog no. ab55305; dilution, 1:100) or anti-Foxp3 antibody (catalog no. ab20034; dilution, 1:100) (both from Abcam, Cambridge, UK) in normal swine serum at $4^{\circ} \mathrm{C}$, in a humidified chamber overnight. Following washing with $0.1 \%$ Tween-20 in PBS, sections were incubated with biotinylated anti-mouse secondary antibody (catalog no. BA-9200; dilution, 1:200; Vector Laboratories, Ltd.) for $1 \mathrm{~h}$ at room temperature in a humidified chamber. Sections were then stained with Vectastain peroxidase ABC kit (Vector Laboratories, Ltd.), according to the manufacturer's protocol. Staining was developed with 3,3'-diaminobenzidine (Sigma-Aldrich; Merck KGaA) and counterstained with Mayer's hematoxylin (Dako; Aglient Technologies, Inc.), according to the manufacturers' protocols. Sections stained with no primary antibody was used as a negative control. Visualization was performed using an optical microscope (Provis AX-70; Olympus Corporation, Tokyo, Japan).

High-performance liquid chromatography (HPLC). HPLC was performed on a Shimadzu LC-10ADVP system (Shimadzu Corporation, Kyoto, Japan). The separation was performed isocratically using a Cronusil-S ODS1 (250x4.6-mm) column (SMI-LabHut, Ltd., Gloucester, UK) at $25^{\circ} \mathrm{C}$ at a flow rate of $1 \mathrm{ml} / \mathrm{min}$. The mobile phase contained $15 \mathrm{mM}$ sodium acetate ( $\mathrm{pH} 5.0)$ and acetonitrile [94:6\% (v/v)]. Following injection $(25 \mu \mathrm{l})$, the eluted Kyn was monitored at $360 \mathrm{~nm}$ between 0 and $8.5 \mathrm{~min}$, and after $8.5 \mathrm{~min}$, tryptophan was monitored at $278 \mathrm{~nm}$. A working-top standard solution containing $10 \mu \mathrm{M}$ Kyn and $100 \mu \mathrm{M}$ tryptophan was made in mobile phase and further diluted to create a standard curve. Standard or sample $(200 \mu \mathrm{l})$ was mixed with $50 \mu \mathrm{l}$ sulfosalicylic acid, incubated on ice for $15 \mathrm{~min}$ and clarified by centrifugation for $15 \mathrm{~min}$ at $18,000 \mathrm{x} \mathrm{g}$ at $4^{\circ} \mathrm{C}$. Supernatant $(25 \mu \mathrm{l})$ was injected into the HPLC system. Kyn typically eluted at $\sim 6.5 \mathrm{~min}$ and tryptophan at $9.4 \mathrm{~min}$. Standard curve and sample quantification was based on peak area using LCSolution software (version 1.11SP1; Shimadzu Corporation).

Colorimetric assay. Kyn was measured spectrophotometrically, as described previously (33). A total of $75 \mu 130 \%$ trichloroacetic acid was added to $100 \mu \mathrm{l}$ of the culture supernatant, vortexed and centrifuged at $10,000 \times \mathrm{g}$ for $5 \mathrm{~min}$ at $4^{\circ} \mathrm{C}$. Following this, a $75-\mu 1$ volume of the supernatant was then added to an equal volume of Ehrlich's reagent (100 mg dimethylbenzaldehyde and $5 \mathrm{ml}$ glacial acetic acid) in a microtiter plate well. Optical density was measured at 492-nm using a Multiskan MS microplate reader (Thermo Labsystems, Santa Rosa, CA, USA). A standard curve of defined Kyn concentration $(0-100 \mu \mathrm{M})$ permitted analysis of unknowns.

Tryptophan metabolites. 3-Hydroxykynurenine (3-HK), Kyn and 3-hydroxyanthranilic acid (3-HAA) (all from Sigma-Aldrich; Merck KGaA) were dissolved in RPMI-1640 medium and added to $\mathrm{CD} 4^{+} \mathrm{T}$ cells in culture at concentrations between 0 and $100 \mu \mathrm{M}(\mathrm{pH} 7.5-8.5)$.

Isolation of human $C D 4^{+} T$-cells. Isolation of human $\mathrm{CD}^{+} \mathrm{T}$ cells was performed using Rosette Sep (Stemcell Technologies, Vancouver, BC, Canada) human CD4 ${ }^{+} \mathrm{T}$-cell enrichment cocktail at $50 \mu \mathrm{l} / \mathrm{ml}$ of whole blood $(500 \mu \mathrm{l} / 10 \mathrm{ml})$, according to the manufacturer's protocol. Briefly, the whole blood was taken from a healthy donor and incubated with the cocktail for $20 \mathrm{~min}$ at room temperature. The sample was diluted with an equal volume of PBS (plus 2\% FBS) and mixed gently. This was layered on top of the density medium and centrifuged at $1,200 \mathrm{x}$ g for $20 \mathrm{~min}$ at room temperature. The enriched cells were isolated from the density medium-plasma interface and washed with PBS with $2 \%$ FBS. Isolated CD4 ${ }^{+} \mathrm{T}$ cells $\left(1 \times 10^{5}\right.$ cells/well) were stimulated with anti-human CD3 and CD28 beads at the ratio of one bead per cell (Dynabeads Human T-activator; Invitrogen; Thermo Fisher Scientific, Inc.) in the presence of tryptophan metabolites, 3-HK, 3-HAA and L-Kyn (Sigma-Aldrich; Merck KGaA) at $50 \mu \mathrm{M}$ concentration, with $10 \mathrm{ng} / \mathrm{ml}$ TGF- $\beta 1$ (R\&D Systems Europe, Ltd., Abingdon, UK) used as a control; cells were incubated for 5 days.

Intracellular staining of T-regulatory cells. Intracellular staining for Foxp3 was performed using a Foxp3 intracellular staining kit (eBioscience; Thermo Fisher Scientific, Inc.), according to the manufacturer's protocol. This kit has been formulated and optimized to stain intracellular antigen Foxp3 (clone: PCH101; allophycocyanin, catalog no. 17-4776-42; eBioscience $^{\mathrm{TM}}$, Invitrogen; Thermo Fisher Scientific, Inc.). Cells were stained for intracellular staining. Briefly, cells suspended in FACS tubes were pelleted by centrifugation at $500 \mathrm{x} \mathrm{g}$ for $5 \mathrm{~min}$ at $4^{\circ} \mathrm{C}$. Following removal of the supernatant, cells were fixed in a fixation/permeabilization buffer (1-part fixation/permeabilization concentrate to 3 parts fixation/permeabilization diluent) for $30 \mathrm{~min}$ at $4^{\circ} \mathrm{C}$. Cells were then washed and centrifuged in permeabilization buffer at $500 \mathrm{x} \mathrm{g}$ for $5 \mathrm{~min}$ (at $4^{\circ} \mathrm{C}$ ) followed by 1 -h incubation with the primary antibody. Finally, cells were washed twice in permeabilization buffer prior to re-suspension in FACS buffer (PBS with 2\% FBS) and analyzed using a FACSCanto II flow cytometer and BD FACSDiva ${ }^{\mathrm{TM}}$ software, version 7.0 (both from BD Biosciences, Franklin Lakes, NJ, USA).

Statistical analysis. Statistical analysis was performed using GraphPad Prism 5.0 (GraphPad Software, Inc., La Jolla, CA, USA). Unless otherwise noted, data represent the mean value of an experiment conducted in triplicate \pm standard error of the mean. For comparison between 2 groups, unpaired two-tailed Student's t-tests or Mann Whitney unpaired t-test were performed. For $\geq 3$ groups, a one-way analysis of variance test was performed and, if significant, a post-hoc Tukey's analysis was performed. $\mathrm{P}<0.05$ was considered to indicate a statistically significant difference.

\section{Results}

Expression of IDO in iBECs. A prior study established an in vitro model using iBECs to investigate the link between senescence and epithelial cell de-differentiation (30). The 

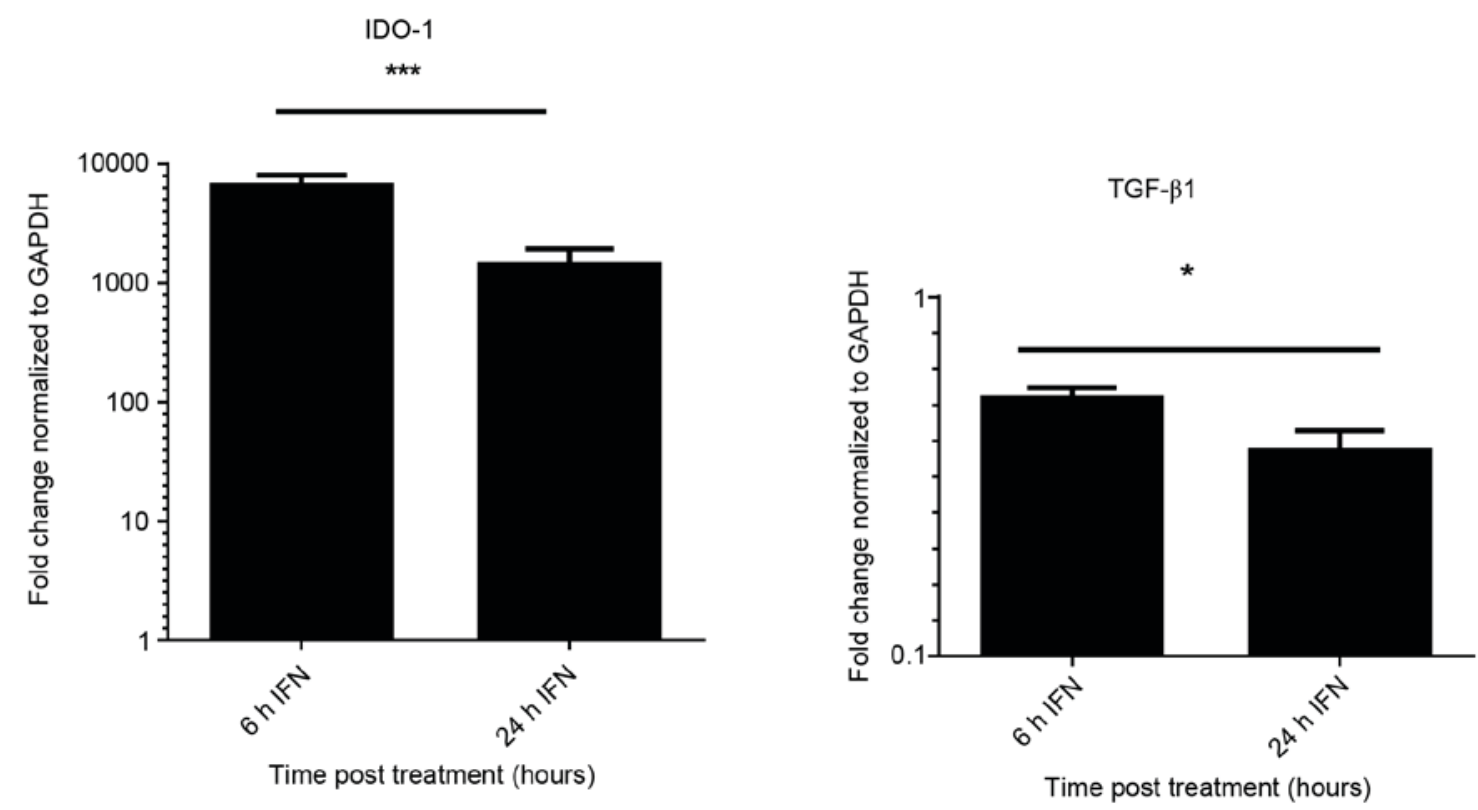

IDO-2
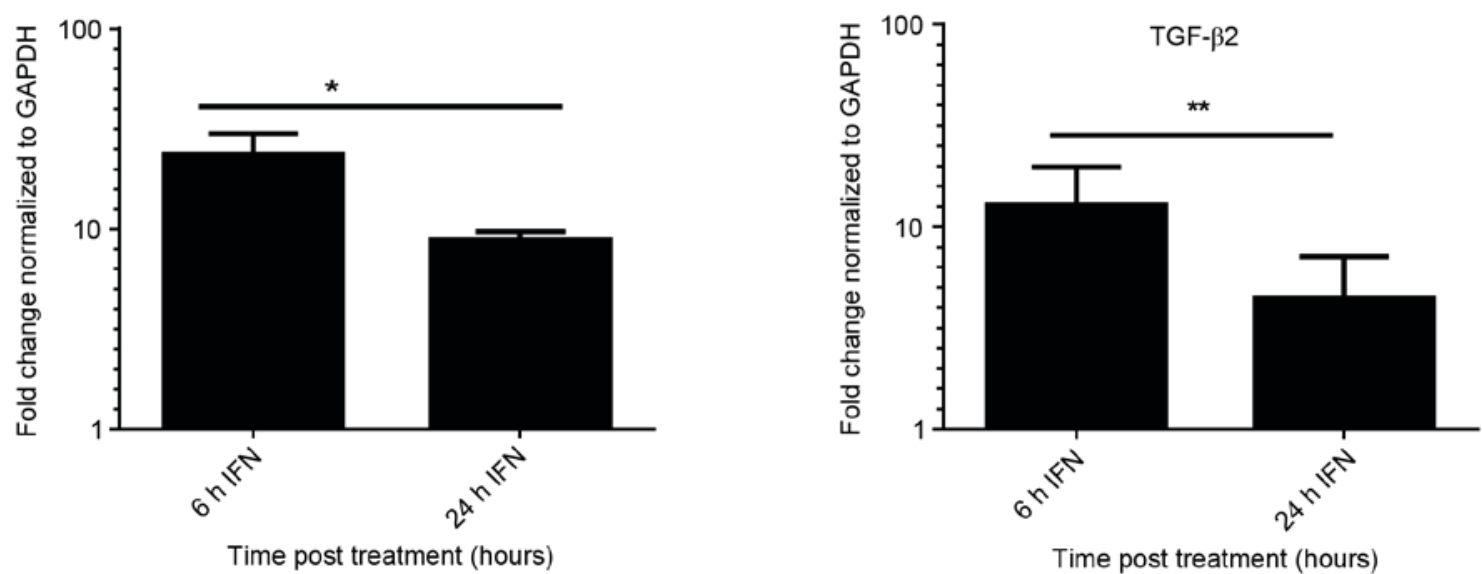

Figure 1. Quantification of IDO-1/2 and TGF- $\beta 1 / 2$ mRNA in immortalized biliary epithelial cells. Cells were treated with IFN- $\gamma(20 \mathrm{ng} / \mathrm{ml})$ for 6 and $24 \mathrm{~h}$. RNA was extracted and cDNA was prepared. mRNA for target genes was normalized to GAPDH and compared to unstimulated cells using quantitative polymerase chain reaction analysis. Data are presented as the mean of the results of three individual experiments; error bars indicate standard deviation ${ }^{* * *} \mathrm{P}<0.05$ vs. 6 h IFN, ${ }^{* *} \mathrm{P}<0.05$ vs. 6 h IFN, ${ }^{*} \mathrm{P}<0.01$ vs. 6 h IFN. IDO, indoleamine 2,3 -dioxygenase; TGF- $\beta$, transforming growth factor $-\beta ;$ IFN- $\gamma$, interferon- $\gamma$.

present study assessed the expression of mRNA encoding IDO-1, IDO-2, TGF- $\beta 1$ and TGF- $\beta 2$ following stimulation of iBEC with IFN- $\gamma$, for 6 and 24 h. Fig. 1 demonstrates the significant increase $(\mathrm{P}<0.05)$ in the expression of IDO-1 $(6,644-$ fold $)$ with IFN- $\gamma$ at $6 \mathrm{~h}$. The results shown were normalized against the housekeeping gene GAPDH. High levels of IDO-1 expression were sustained at $24 \mathrm{~h}$ in IFN- $\gamma$ treated cells; whereas no detectable expression of IDO-1 was found in untreated iBECs (data not shown).

Increase in IDO-2 expression was observed in cells treated with IFN- $\gamma(\mathrm{P}<0.01)$. Expression of TGF- $\beta 2$ was also upregulated (12-fold) upon treatment with IFN- $\gamma$ at $6 \mathrm{~h}$, but expression was reduced at $24 \mathrm{~h}$. There was no significant increase in expression of TGF- $\beta 1$ following stimulation with IFN- $\gamma$; however, TGF- $\beta 2$ expression was significantly increased.
To determine whether IDO-1 expression is dependent on the TGF- $\beta$ pathway, cells were incubated with an ALK5 inhibitor (SB-505124) at an optimal concentration of $1 \mu \mathrm{M}$ (30) for $1 \mathrm{~h}$ prior to stimulation with IFN- $\gamma$ for 6 and $24 \mathrm{~h}$. The expression of IDO-1 was not significantly different in the treated or the untreated group ( $\mathrm{P}>0.05$, data not shown). These findings suggest that IDO-1 expression in iBEC is inducible, with a marked increase following IFN- $\gamma$ stimulation, but independent of the TGF- $\beta$ pathway.

Enzymatic activity of IDO is upregulated by IFN- $\gamma$ stimulation in iBECs. Certain studies have revealed an inconsistency between the expression of IDO and its enzymatic activity $(34,35)$; thus, the present study examined the enzymatic activity of IDO in iBECs. A colorimetric assay was used to measure the levels of Kyn in the culture supernatant (Fig. 2). 


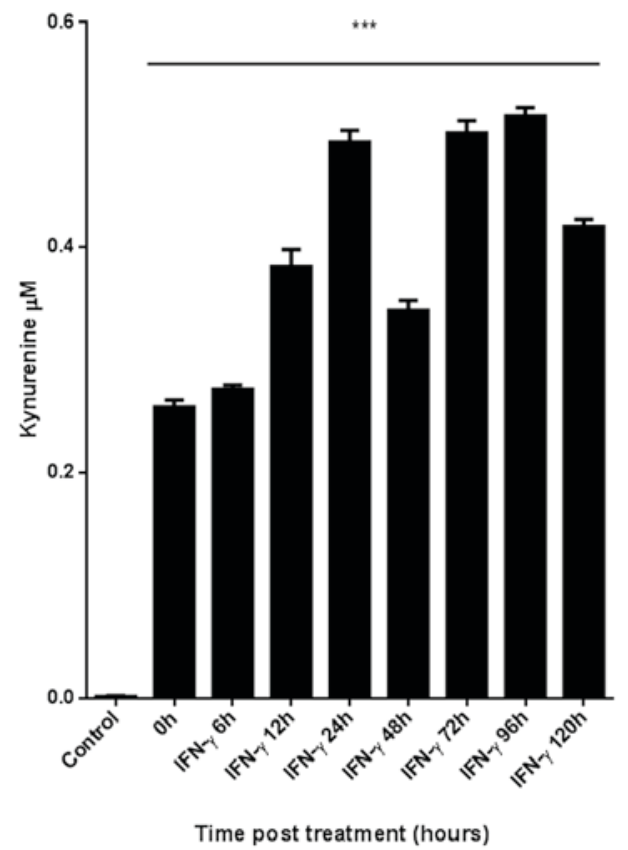

Figure 2. Measurement of IDO enzymatic activity in immortalized biliary epithelial cell supernatants. Enzymatic activity was quantified by the colorimetric assay for kynurenine, in the presence of IFN- $\gamma(20 \mathrm{ng} / \mathrm{ml})$ for 0 to $120 \mathrm{~h}$. IFN $-\gamma$, interferon $\gamma$. The difference was significant $\left.{ }^{(* * *} \mathrm{P}<0.05\right)$ between the supernatant of stimulated and unstimulated (control) cells.

Cells were stimulated with IFN- $\gamma$ for up to $120 \mathrm{~h}$. The supernatant of unstimulated iBEC produced no Kyn. The difference in Kyn levels between the IFN- $\gamma$-stimulated and the unstimulated iBECs was significant $(\mathrm{P}<0.05)$.

IDO activity in PBC patient sera. IDO activity was measured by assessing the ratio of the enzyme substrate tryptophan and its product Kyn (Fig. 3). Higher IDO activity was observed in the sera of PBC patients $(n=47)$ compared with the healthy controls $(n=24)$. Statistically significant differences were found between the two groups when measuring the area and height of peaks as determined by HPLC (Fig. 3).

Expression of IDO in BECs from the patients with PBC. To assess IDO expression in PBC, an immunohistochemical assay was performed. Expression of IDO in the liver tissue was examined in samples from healthy controls $(n=5)$ and patients with PBC $(n=5)$. No expression was observed in the cholangiocytes of healthy controls (Fig. 4A). Fig. 4B-D reveals IDO expression in late-stage PBC. Discrete staining is revealed in the BECs (Fig. 4B). IDO expression was increased in periportal hepatocytes, in conjunction with notable interface hepatitis (Fig. 4C and D). Sections from matched PBC patients stained for Foxp3 are presented in Fig. 4E and F; Foxp $3^{+}$cells were morphologically small lymphocytes. There was an evident increase in the number of inflammatory cells, particularly those with interface hepatitis and IDO expression.

Tryptophan metabolites induce the T-reg phenotype from the whole human $C D 4^{+} T$ cell population. IDO may induce T-regs, at least in part, through certain tryptophan metabolites. To test this, human $\mathrm{CD} 4^{+} \mathrm{T}$ cells were stimulated with
anti-CD3/CD28 beads in the presence of $50 \mu \mathrm{M}$ of the Kyns, L-Kyn, 3-HK and 3-HAA for 5 days. T-reg development was assessed by analyzing Foxp3 expression with flow cytometry.

There was no significant difference in the proportion of $\mathrm{CD} 4{ }^{+}$cells expressing Foxp3 in the presence of L-Kyn and 3-HAA compared with the control after 5 days (Fig. 5); however, 3-HK was significantly upregulated in the fraction of CD4 ${ }^{+}$cells expressing Foxp3.

\section{Discussion}

To the best of our knowledge, the current study establishes the expression of IDO in H69 iBECs for the first time, and reveals the increased rate of conversion of tryptophan to Kyn in patients with PBC. Furthermore, clinical biopsies from PBC patients demonstrated that the expression of IDO was observed not only in BECs, as described previously (8), but also in hepatocytes.

The transcriptional profile of IDO in iBECs was assessed following direct stimulation with IFN- $\gamma$, and levels were found to be significantly increased. IFN- $\gamma$ induced IDO expression in the iBECs. This suggests that the expression of IDO in iBECs is highly responsive to IFN- $\gamma$ stimulation. Data from the present study is in agreement with earlier studies, which revealed that IFN- $\gamma$ can induce IDO expression in several cell types and is produced by inflammatory cells in response to immune activation (36-38). This expression occurs during infectious, autoimmune and malignant diseases $(2,3)$.

Although the majority of past research has focused on IDO as the central and immunobiologically relevant enzyme that catalyzes the conversion of tryptophan to Kyn, there are two additional enzymes, IDO-2 and tryptophan-2,3-dioxygenase (TDO), which can catalyze the same enzymatic reaction. TDO was first detected in the liver; however, little is known about the role of TDO in tumorigenesis or its association with IDO (39). IDO-2 was recently identified and has slightly different expression pattern to IDO-1 (6). In the present study, the regulation of IDO-2 was examined in response to IFN- $\gamma$. Unstimulated BECs do not express IDO-2; however, a significant increase in IDO-2 expression was observed following treatment with IFN- $\gamma$.

TGF- $\beta$ is an immunoregulatory cytokine produced by activated T cells that mediates its effect through TGF- $\beta$ receptors 1 and 2. A previous study demonstrated that CD8- DCs can induce IDO in response to TGF- $\beta$ which can modify the cells from immunogenic into a tolerogenic state (40). Upon examination of the expression of TGF- $\beta$ receptors 1 and 2 , TGF- $\beta$ receptor 1 levels were not significantly altered, whereas TGF- $\beta$ receptor 2 levels were significantly increased in response to IFN- $\gamma$. Furthermore, incubation of cells with the non-toxic pharmacological TGF- $\beta$ receptor 1 inhibitor, SB-505124, followed by stimulation with IFN- $\gamma$ had no effect on IDO-1 expression (data not shown). This suggests that, in BECs, the induction of IDO is IFN- $\gamma$-dependent, but independent of the TGF- $\beta$ pathway.

The enzymatic activity of IDO was examined in H69 cells in the present study. Increased Kyn production and reduced substrate tryptophan demonstrated that IDO was enzymatically functional in H69 cells. Additionally, significantly higher IDO activity was observed in sera derived from PBC patients compared with that from healthy controls. However, this 
A

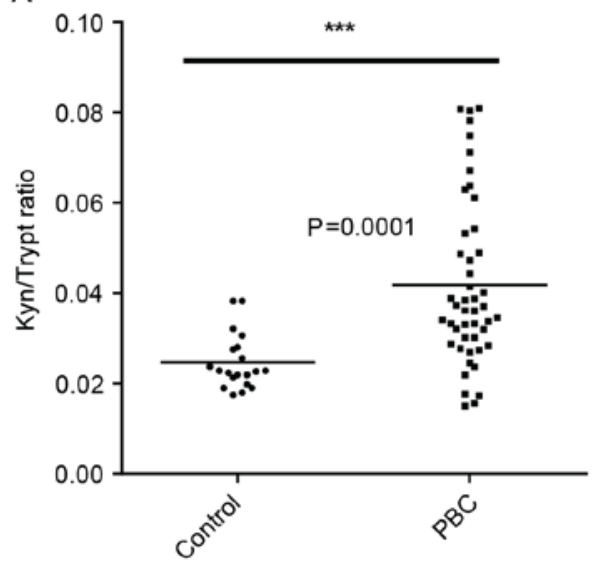

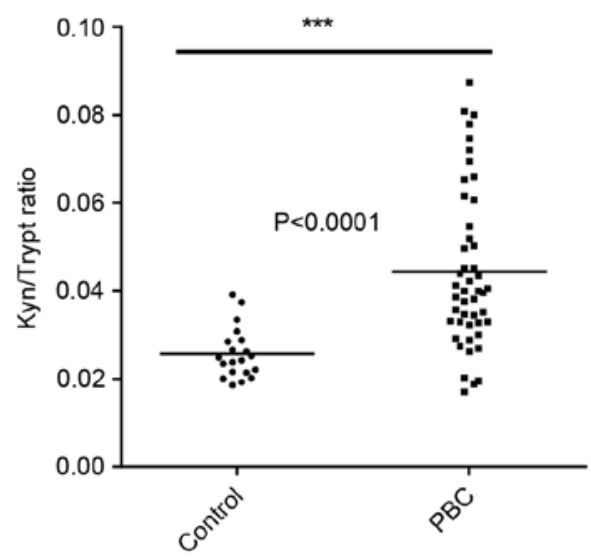

Figure 3. IDO enzymatic activity in human serum samples analyzed by HPLC. Kyn and tryptophan concentrations were measured by high-performance liquid chromatography in serum samples collected from 24 healthy donors and 47 PBC patients. The Mann Whitney unpaired t-test statistical analysis was used to compare the control and patient groups. (A) Kyn and tryptophan ratio (area under peak). (B) Kyn and tryptophan ratio (height of peaks). Kyn, kynurenine; Trypt, tryptophan; IDO, indoleamine 2,3-dioxygenase; PBC, primary biliary cirrhosis.

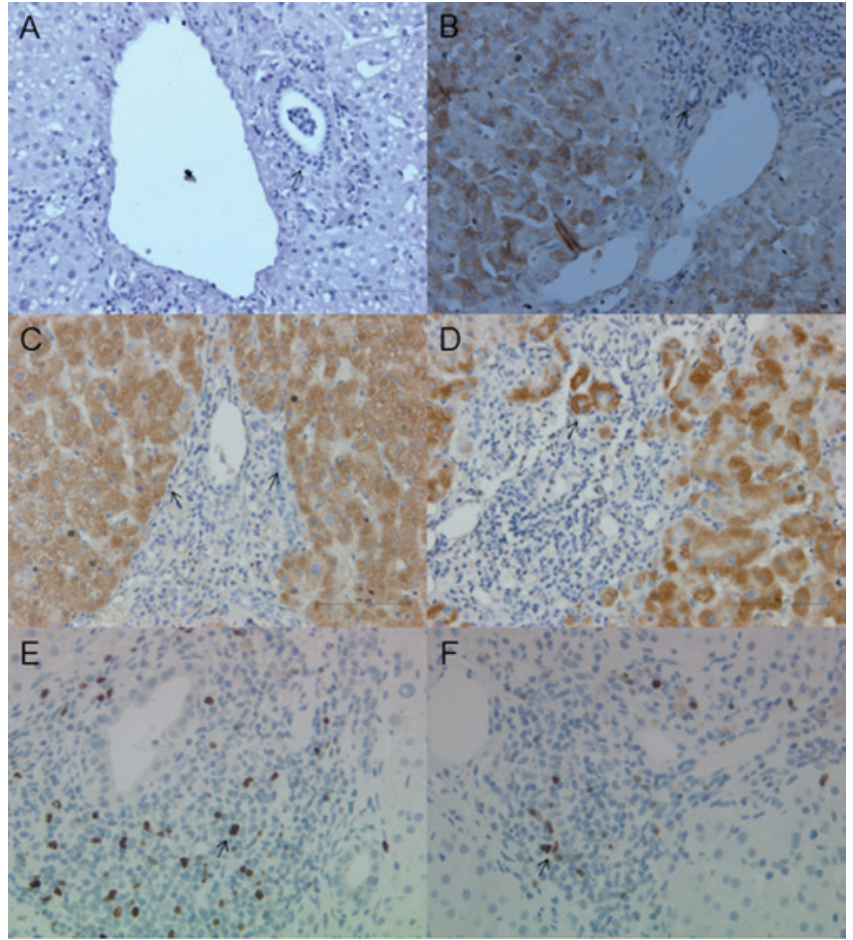

Figure 4. Expression of IDO and Foxp3 in PBC liver biopsies. The expression of IDO in liver tissues was examined in samples from healthy controls $(n=5)$ and patients with PBC $(n=5)$. (A) No IDO expression was observed in BECs of healthy controls. (B) Discrete IDO staining is observed in the BECs of patients with PBC. (C) IDO expression was markedly increased in periportal hepatocytes in conjunction with notable interface hepatitis. (D) A typical clustering of IDO positivity was observed in hepatocytes. Sections from matched PBC patients stained for Foxp3: (E) Foxp3 positive cells were detected and (F) infiltrating cells were positive for Foxp3. There is an increase in the number of inflammatory T-reg cells, particularly with interface hepatitis and IDO expression. Original images were captured at x100 magnification. Arrows indicate the expression of IDO and Foxp3, respectively. IDO, indoleamine 2,3-dioxygenase; PBC, primary biliary cirrhosis; BECs, biliary epithelial cells; Foxp3, forkhead box P3.

pathway is extremely responsive to non-specific inflammation and is induced in all states of chronic inflammation, as IDO is an extremely sensitive IFN- $\gamma$ responsive gene.

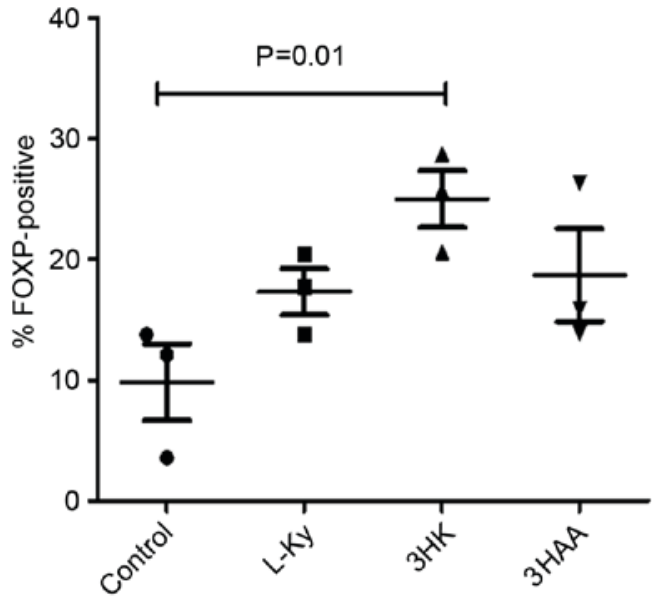

Figure 5. Foxp3 expression in human $\mathrm{CD}^{+}{ }^{+} \mathrm{T}$ cells cultured with Kyns. CD4 ${ }^{+}$ $\mathrm{T}$ cells were activated with anti-CD3/CD28 beads in the presence or absence of the indicated Kyns. At 5 days, cells were retrieved and the proportion of $\mathrm{CD}^{+} \mathrm{T}$ cells that were Foxp3-positive was determined by intracellular flow cytometry. Results are representative of at least three independent experiments. L-Kyn, kynurenine. CD, cluster of differentiation; Foxp3, forkhead box p3; 3-HK, 3-hydroxykynurenine; 3-HAA, 3-hydroxyanthranilic acid.

Liver sections from PBC patients were examined and it was confirmed that IDO is expressed in hepatocytes, as it is in other epithelial cells $(41,42)$. Low-level expression of IDO was identified within BECs and strong expression was observed in hepatocytes, which indicates its potential role in PBC. Liver sections from matched patients with PBC expressed Foxp3. There was an increase in the number of inflammatory cells, particularly those exhibiting interface hepatitis and IDO expression. IDO was recognized in early stage PBC samples and within damaged cholangiocyte aggregates, identifying its role in immunogenicity and indicating its involvement in PBC (8).

The tryptophan metabolite 3 -HK significantly upregulated Foxp3 in human $\mathrm{CD}^{+} \mathrm{T}$ cells, thus polarizing the response towards a T-reg phenotype. In agreement with the data from the current study, prior research by Fallarino et al (21), found that tryptophan catabolites downregulate the expression of 
T-cell receptor- $\zeta$-chain and induce a regulatory phenotype in naïve $\mathrm{T}$ cells.

IDO activity is increased in autoimmune disorders and inflammation (43). In animal models of autoimmunity, such as that of experimental autoimmune encephalomyelitis (EAE), the presence of IDO-produced tryptophan metabolites results in the skewing of a Th1 immune response towards a Th2 response, which results in reduced inflammation and tissue damage. Notably, a tryptophan metabolite, 3,4,'-dimethoxycinnamoyl anthranilic acid, was able to reverse paralysis in mice with EAE (44). IDO immunosuppressive action serves as a negative feedback effect induced by hyper-activation of T-cell immunity. In the present study, although the Kyn/tryptophan ratio was increased in PBC patients, it is possible the level of IDO expression was not sufficient to produce the desired immunosuppression. This raises the possibility that Kyn metabolites could be used in disease resolution.

In conclusion, the present study demonstrated that expression of IDO in iBECs was stimulated by IFN- $\gamma$. The induction of IDO at the tissue level may serve a role in the pathogenesis of $\mathrm{PBC}$. The effect of tryptophan metabolites on human $\mathrm{CD} 4^{+} \mathrm{T}$ cells in inducing polarization towards a T-reg phenotype suggests that there exists a therapeutic opportunity for the management of PBC. Furthermore, tryptophan catabolism could act as a potential biomarker to monitor disease progression in PBC.

\section{Acknowledgements}

The present study was supported by grants from the Marie Curie Innovative Doctoral Programme (grant no. FP7-PEOPLE-2013-ITN), and Medical Research Council UK Primary Biliary Cirrhosis Programme (grant no. MR/L001489/1).

\section{References}

1. Mellor AL and Munn DH: IDO expression by dendritic cells: Tolerance and tryptophan catabolism. Nat Rev Immunol 4: $762-774,2004$

2. Uyttenhove C, Pilotte L, Théate I, Stroobant V, Colau D, Parmentier N, Boon T and Van den Eynde BJ: Evidence for a tumoral immune resistance mechanism based on tryptophan degradation by indoleamine 2,3-dioxygenase. Nat Med 9: 1269-1274, 2003.

3. Curti A, Aluigi M, Pandolfi S, Ferri E, Isidori A, Salvestrini V, Durelli I, Horenstein AL, Fiore F, Massaia M, et al: Acute myeloid leukemia cells constitutively express the immunoregulatory enzyme indoleamine 2,3-dioxygenase. Leukemia 21: 353-355, 2007.

4. Däubener W and MacKenzie CR: IFN-gamma activated indoleamine 2,3-dioxygenase activity in human cells is an antiparasitic and an antibacterial effector mechanism. Adv Exp Med Biol 467: 517-524, 1999.

5. Ball HJ, Sanchez-Perez A, Weiser S, Austin CJ, Astelbauer F, Miu J, McQuillan JA, Stocker R, Jermiin LS and Hunt NH: Characterization of an indoleamine 2,3-dioxygenase-like protein found in humans and mice. Gene 396: 203-213, 2007.

6. Metz R, Duhadaway JB, Kamasani U, Laury-Kleintop L, Muller AJ and Prendergast GC: Novel tryptophan catabolic enzyme IDO2 is the preferred biochemical target of the antitumor indoleamine 2,3-dioxygenase inhibitory compound D-1-methyl-tryptophan. Cancer Res 67: 7082-7087, 2007.

7. Lob S, Konigsrainer A, Schafer R, Rammensee HG, Opelz G and Terness P: Levo- but not dextro-1-methyl tryptophan abrogates the IDO activity of human dendritic cells. Blood 111: 2152-2154, 2008.
8. Oertelt-Prigione S, Mao TK, Selmi C, Tsuneyama K, Ansari AA, Coppel RL, Invernizzi P, Podda M and Gershwin ME: Impaired indoleamine 2,3-dioxygenase production contributes to the development of autoimmunity in primary biliary cirrhosis. Autoimmunity 41: 92-99, 2008.

9. Lan RY, Cheng C, Lian ZX, Tsuneyama K, Yang GX, Moritoki Y, Chuang YH, Nakamura T, Saito S, Shimoda S, et al: Liver-targeted and peripheral blood alterations of regulatory $\mathrm{T}$ cells in primary biliary cirrhosis. Hepatology 43: 729-737, 2006.

10. Shimoda S, Van de Water J, Ansari A, Nakamura M, Ishibashi H, Coppel RL, Lake J, Keeffe EB, Roche TE and Gershwin ME: Identification and precursor frequency analysis of a common $\mathrm{T}$ cell epitope motif in mitochondrial autoantigens in primary biliary cirrhosis. J Clin Invest 102: 1831-1840, 1998.

11. Kita H, Matsumura S, He XS, Ansari AA, LianZX, Van de Water J, Coppel RL, Kaplan MM and Gershwin ME: Quantitative and functional analysis of PDC-E2-specific autoreactive cytotoxic T lymphocytes in primary biliary cirrhosis. J Clin Invest 109 : 1231-1240, 2002

12. Grohmann U, Fallarino F and Puccetti P: Tolerance, DCs and tryptophan: Much ado about IDO. Trends Immunol 24: 242-248, 2003.

13. Munn DH, Sharma MD and Mellor AL: Ligation of B7-1/B7-2 by human $\mathrm{CD}^{+} \mathrm{T}$ cells triggers indoleamine 2,3-dioxygenase activity in dendritic cells. J Immunol 172: 4100-4110, 2004.

14. Munn DH, Sharma MD, Baban B, Harding HP, Zhang Y, Ron D and Mellor AL: GCN2 kinase in T cells mediates proliferative arrest and anergy induction in response to indoleamine 2,3-dioxygenase. Immunity 22: 633-642, 2005.

15. Mezrich JD, Fechner JH, Zhang X, Johnson BP, Burlingham WJ and Bradfield CA: An interaction between kynurenine and the aryl hydrocarbon receptor can generate regulatory $\mathrm{T}$ cells. J Immunol 185: 3190-3198, 2010.

16. Terness P, Bauer TM, Röse L, Dufter C, Watzlik A, Simon H and Opelz G: Inhibition of allogeneic $\mathrm{T}$ cell proliferation by indoleamine 2,3-dioxygenase-expressing dendritic cells: Mediation of suppression by tryptophan metabolites. J Exp Med 196: 447-457, 2002.

17. Frumento G, Rotondo R, Tonetti M, Damonte G, Benatti U and Ferrara GB: Tryptophan-derived catabolites are responsible for inhibition of $\mathrm{T}$ and natural killer cell proliferation induced by indoleamine 2,3-dioxygenase. J Exp Med 196: 459-468, 2002.

18. Fallarino F, Grohmann U, Vacca C, Bianchi R, Orabona C, Spreca A, Fioretti M and Puccetti P: T cell apoptosis by tryptophan catabolism. Cell Death Differ 9: 1069-1077, 2002.

19. Fallarino F, Grohmann U, Vacca C, Orabona C, Spreca A, Fioretti MC and Puccetti P: T cell apoptosis by kynurenines. Adv Exp Med Biol 527: 183-190, 2003.

20. Seman M, Adriouch S, Scheuplein F, Krebs C, Freese D, Glowacki G, Deterre P, Haag F and Koch-Nolte F: NAD-induced T cell death: ADP-ribosylation of cell surface proteins by ART2 activates the cytolytic P2X7 purinoceptor. Immunity 19: 571-582, 2003.

21. Fallarino F, Grohmann U, You S, McGrath BC, Cavener DR, Vacca C, Orabona C, Bianchi R, Belladonna ML, Volpi C, et al: The combined effects of tryptophan starvation and tryptophan catabolites down-regulate $T$ cell receptor zeta-chain and induce a regulatory phenotype in naive T cells. J Immunol 176: 6752-6761, 2006.

22. Rubtsov YP and Rudensky AY: TGFbeta signalling in control of T-cell-mediated self-reactivity. Nat Rev Immunol 7: 443-453, 2007.

23. Belladonna ML, Volpi C, Bianchi R, Vacca C, Orabona C, Pallotta MT, Boon L, Gizzi S, Fioretti MC, Grohmann U and Puccetti P: Cutting edge: Autocrine TGF-beta sustains default tolerogenesis by IDO-competent dendritic cells. J Immunol 181: 5194-5198, 2008.

24. Yuan W, Collado-Hidalgo A, Yufit T, Taylor M and Varga J: Modulation of cellular tryptophan metabolism in human fibroblasts by transforming growth factor-beta: Selective inhibition of indoleamine 2,3-dioxygenase and tryptophanyl-tRNA synthetase gene expression. J Cell Physiol 177: 174-186, 1998.

25. MacKenzie CR, González RG, Kniep E, Roch S and Däubener W: Cytokine mediated regulation of interferon-gamma-induced IDO activation. Adv Exp Med Biol 467: 533-539, 1999.

26. Thomas SR, Mohr D and Stocker R: Nitric oxide inhibits indoleamine 2,3-dioxygenase activity in interferon-gamma primed mononuclear phagocytes. J Biol Chem 269: 14457-14464, 1994.

27. Martinez OM, Villanueva JC, Gershwin ME and Krams SM: Cytokine patterns and cytotoxic mediators in primary biliary cirrhosis. Hepatology 21: 113-119, 1995. 
28. Neuman M, Angulo P, Malkiewicz I, Jorgensen R, Shear N, Dickson ER, Haber J, Katz G and Lindor K: Tumor necrosis factor-alpha and transforming growth factor-beta reflect severity of liver damage in primary biliary cirrhosis. J Gastroenterol Hepatol 17: 196-202, 2002.

29. Grubman SA, Perrone RD, Lee DW, Murray SL, Rogers LC, Wolkoff LI, Mulberg AE, Cherington V and Jefferson DM: Regulation of intracellular $\mathrm{pH}$ by immortalized human intrahepatic biliary epithelial cell lines. Am J Physiol 266: G1060-G1070, 1994.

30. Brain JG, Robertson H, Thompson E, Humphreys EH, Gardner A, Booth TA, Jones DE, Afford SC, von Zglinicki T, Burt AD and Kirby JA: Biliary epithelial senescence and plasticity in acute cellular rejection. Am J Transplant 13: 1688-1702, 2013.

31. Chomczynski P and Sacchi N: Single-step method of RNA isolation by acid guanidinium thiocyanate-phenol-chloroform extraction. Anal Biochem 162: 156-159, 1987.

32. Livak KJ and Schmittgen TD: Analysis of relative gene expression data using real-time quantitative PCR and the 2(-Delta Delta C(T)) method. Methods 25: 402-408, 2001.

33. Takikawa O, Kuroiwa T, Yamazaki F and Kido R: Mechanism of interferon-gamma action. Characterization of indoleamine 2,3-dioxygenase in cultured human cells induced by interferon-gamma and evaluation of the enzyme-mediated tryptophan degradation in its anticellular activity. J Biol Chem 263: 2041-2048, 1988.

34. Laich A, Neurauter G, Widner B and Fuchs D: More rapid method for simultaneous measurement of tryptophan and kynurenine by HPLC. Clin Chem 48: 579-581, 2002.

35. Hwu P, Du MX, Lapointe R, Do M, Taylor MW and Young HA: Indoleamine 2,3-dioxygenase production by human dendritic cells results in the inhibition of $\mathrm{T}$ cell proliferation. J Immunol 164: 3596-3599, 2000.

36. Billiau A and Matthys P: Interferon-gamma: A historical perspective. Cytokine Growth Factor Rev 20: 97-113, 2009.
37. Sakash JB, Byrne GI, Lichtman A and Libby P: Cytokines induce indoleamine 2,3-dioxygenase expression in human atheroma-associated cells: Implications for persistent Chlamydophila pneumoniae infection. Infect Immun 70: 3959-3961, 2002.

38. Munn DH, Sharma MD, Lee JR, Jhaver KG, Johnson TS, Keskin DB, Marshall B, Chandler P, Antonia SJ and Burgess R: Potential regulatory function of human dendritic cells expressing indoleamine 2,3-dioxygenase. Science 297: 1867-1870, 2002.

39. Knox WE and Mehler AH: The conversion of tryptophan to kynurenine in liver I. The coupled tryptophan peroxidase-oxidase system forming formylkynurenine. J Biol Chem 187: 419-430, 1950.

40. Viñals $\mathrm{F}$ and Pouysségur J: Transforming growth factor beta1 (TGF-beta1) promotes endothelial cell survival during in vitro angiogenesis via an autocrine mechanism implicating TGF-alpha signaling. Mol Cell Biol 21: 7218-7230, 2001.

41. Shirey KA, Jung JY, Maeder GS and Carlin JM: Upregulation of IFN-gamma receptor expression by proinflammatory cytokines influences IDO activation in epithelial cells. J Interferon Cytokine Res 26: 53-62, 2006.

42. Zegarra-Moran O, Folli C, Manzari B, Ravazzolo R, Varesio L and Galietta LJ: Double mechanism for apical tryptophan depletion in polarized human bronchial epithelium. J Immunol 173: $542-549,2004$.

43. Schröcksnadel K, Wirleitner B, Winkler C and Fuchs D: Monitoring tryptophan metabolism in chronic immune activation. Clin Chim Acta 364: 82-90, 2006.

44. Platten M, Ho PP, Youssef S, Fontoura P, Garren H, Hur EM, Gupta R, Lee LY, Kidd BA, Robinson WH, et al: Treatment of autoimmune neuroinflammation with a synthetic tryptophan metabolite. Science 310: 850-855, 2005. 